\title{
Does temperature affect the accuracy of vented pressure transducer in fine-scale water level measurement?
}

\author{
Z. Liu and C. W. Higgins \\ Department of Biological and Ecological Engineering, Oregon State University, Corvallis, Oregon, 97331, USA \\ Correspondence to: Z. Liu (ziru.liu@ oregonstate.edu)
}

Received: 2 August 2014 - Published in Geosci. Instrum. Method. Data Syst. Discuss.: 29 September 2014

Revised: 13 January 2015 - Accepted: 1 February 2015 - Published: 3 March 2015

\begin{abstract}
Submersible pressure transducers have been utilized for collecting water level data since the early 1960s. Together with a digital data logger, it is a convenient way to record water level fluctuations for long-term monitoring. Despite the wide use of pressure transducers for water level monitoring, little has been reported regarding their accuracy and performance under field conditions. The effects of temperature fluctuations on the output of vented pressure transducers were considered in this study. The pressure transducers were tested under both laboratory and field conditions. The results of this study indicate that temperature fluctuation has a strong effect on the transducer output. Rapid changes in temperature introduce noise and fluctuations in the water level readings under a constant hydraulic head while the absolute temperature is also related to sensor errors. The former is attributed to venting and the latter is attributed to temperature compensation effects in the strain gauges. Individual pressure transducers responded differently to the thermal fluctuations in the same testing environment. In the field of surface hydrology, especially when monitoring fine-scale water level fluctuations, ignoring or failing to compensate for the temperature effect can introduce considerable error into pressure transducer readings. It is recommended that a performance test for the pressure transducer is conducted before field deployment.
\end{abstract}

\section{Introduction}

Submersible gauge pressure transducers are used to monitor water level fluctuation in wells and flow in open channels. Combined with a digital data logger, pressure transducers can be a useful and cost effective tool in the field of hydrology (Rosenberry, 1990; Freeman et al., 2004; McDonald, 2011).

There are two types of submersible pressure transducers. The first is vented to the atmosphere through an integral air tube which allows for automatic compensation of barometric pressure change. This type is often referred to as a gauge pressure transducer. The second type measures the combined atmospheric pressure and the pressure head exerted by the overlying water column. This type is known as an absolute pressure transducer. For this type, the barometric pressure needs to be recorded separately to calculate the water level (Post and von Asmuth, 2013).

Despite the wide use of submersible pressure transducers in water level monitoring, little has been discussed about their accuracy and long-term performance. The accuracy of pressure transducers varies among models and manufacturers. Currently there is no industry-wide standard for the calibration of pressure transducers which makes the direct comparison of results extremely difficult (Sorensen and Butcher, 2011). Moreover, the pressure transducers are usually calibrated by manufacturers in their laboratory where the environmental factors are well-controlled, e.g., temperature. However, the performance of the pressure transducer in the laboratory does not equally translate to its field performance, especially when monitoring surface water flow where diurnal fluctuations of temperature and humidity exist.

The accuracy of pressure transducers has been examined in some recent articles. Instrument drift has been found in different branded sensors (Sorensen and Butcher, 2011). The thermal effect on the sensitivity of the pressure transducer was also discussed (Cain et al., 2004; Mclaughlin and Cohen, 2011; Gribovszki et al., 2013). Cain et al. (2004) investigated the noise in pressure transducer readings by measuring a con- 
stant water head when the transducer cables were exposed to direct sunlight. They concluded that the noise is caused by the heating and cooling of the air column in the venting tube inside the cable and that the error can be up to $3 \mathrm{~cm}$. The results of Cain et al. (2004) shed some light on our understanding of the accuracy of the pressure transducer for it revealed that there is a relationship between the atmospheric temperature and the transducer reading. Yet it also provoked further thoughts which led to the mathematical analysis presented here.

So far there are only scarce data on the accuracy of fine-scale water level measurement with the vented pressure transducer and no field performance has been evaluated. The authors would like to provide information to fill the gap by testing the performance of the vented pressure transducer in fine-scale water level measurement on both laboratory and field scales.

\section{Materials and methods}

\subsection{Laboratory experiment}

Three commercial water level sensors were used in this study (CTD sensor, Decagon Devices Inc., Pullman, WA, USA). All three CTD sensors measure conductivity, temperature, and water level at the same time. The sensor utilizes a vented pressure transducer to measure water level from 0 to $3.5 \mathrm{~m}$. The measurement resolution is $1 \mathrm{~mm}$ and it has an accuracy range of $\pm 0.2 \%$ of full scale at $20^{\circ} \mathrm{C}$. All three sensors have a cable length of $10 \mathrm{~m}$. At the end of the cable there is a $3.5 \mathrm{~mm}$ stereo plug which connects the sensor to a EM50 data logger (Decagon Devices Inc.). The venting port is near the stereo plug. An air channel was built inside the sensor cable to remove the effect of the barometric pressure.

One of the three sensors has a unique feature. There is an injection tube connected to the front side of the diaphragm in the pressure transducer. This tube needs to be filled with water to avoid any air bubbles before field deployment. In the other two pressure transducers, the diaphragm is in direct contacted with the water.

The three sensors were placed in a water bucket at a fixed depth. The total water depth inside the bucket was kept constant. The opening of the bucket was covered to reduce evaporation; however, a venting hole was left to make sure the air above the water surface was vented to the atmosphere. Then the bucket was placed on a concrete surface where all the sensor cables were fully exposed to sunlight. Later the whole setup was moved into a well-vented room with a relatively constant temperature and humidity.

\subsection{Field experiment}

CTD sensors were installed within a roadside filter strip in Oregon: one near Alsea, and one near Stayton (on Santiam Highway). Here, the CTD sensors were used to collect high-

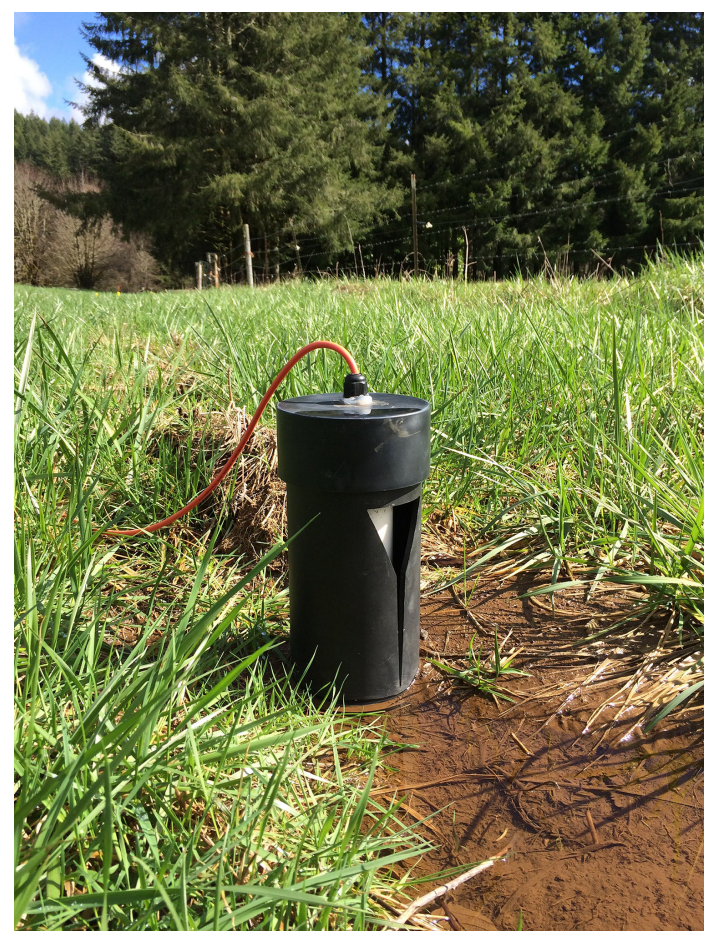

Figure 1. Field installation of a water level sensor inside a flow container.

way surface stormwater runoff data. The sensor was positioned inside a v-notch flow container to monitor water level change which was later converted into runoff flow rate through a rating curve.

Figure 1 shows the field installation of the sensor inside the flow container at the Alsea site, the installation at Santiam site is similar. About $30 \mathrm{~cm}$ of the container was buried into the ground so that the soil would protect the water inside the container from freezing during cold days in winter. The water level is at the bottom of the weir (the v-notch which is cut into the side of the flow container) and the sensor is fixed below the water level. During rainfall events, runoff water is routed through the device via a set of collection pipes. Water level inside the container will rise and the water will flow out through the weir. The water level will fall back to the baseline (at the weir bottom) after the rainfall event stops. A full description of this device is provided in Stewart et al. (2014). During dry days, the water level will drop due to evaporation. The sensor cable was laid on the ground and partially covered by soil and vegetation. An EM50 data logger was used to collect time series data. The measurement interval for both laboratory and field conditions was $1 \mathrm{~min}$. 


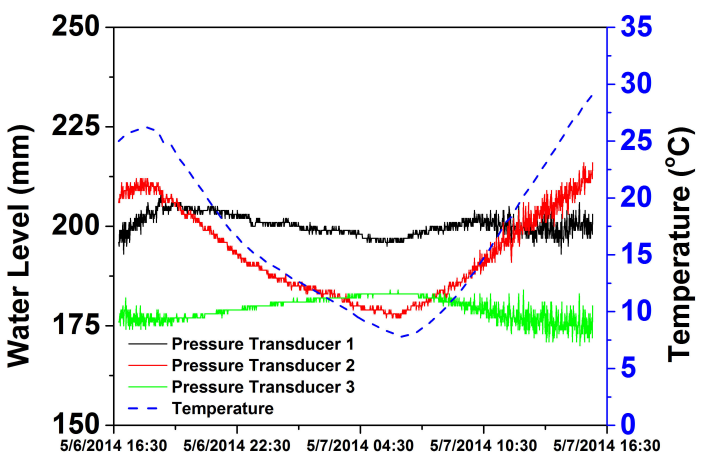

Figure 2. Water levels from three pressure transducers during a $24 \mathrm{~h}$ period when the cables were exposed to sunlight. Left $y$ axis shows the water level measurement and right $y$ axis shows the water temperature inside the bucket.

\section{Results and discussions}

\subsection{Laboratory results}

Figure 2 shows the water level readings for all three pressure transducers and the water temperature in the bucket during a $24 \mathrm{~h}$ period. Some evaporation from the container is inevitable but was controlled so that it would minimally affect the water level readings. The figure clearly shows that temperature has an effect on the pressure transducer. As the temperature increased at the beginning of the test, the transducer readings had more noise and when the temperature dropped during the nighttime, the transducer readings became smoother. Then when the temperature rose from 7.8 to $28.0^{\circ} \mathrm{C}$, more noise can be observed in the readings.

Temperature fluctuation also tends to shift the baseline in the transducer readings. The extent of the effect differs between pressure transducers. This effect is especially strong in pressure transducer 2 . Interestingly, the three pressure transducers did not show a consistent fluctuation pattern with respect to the change in temperature. The high readings in water level corresponded with peaks in temperature for pressure transducers 1 and 2. However, pressure transducer 3 showed an inverse relationship between the water level and temperature readings.

Figure 3 shows the relationships between the temperature and the water level readings. Linear regression was applied for all three sensors. Pressure transducer 2 showed a strong positive correlation between the temperature and the water level with $R^{2}=0.9725$. Pressure transducer 3 showed a clear negative relationship in contrast to pressure transducer 2 . There is also a positive correlation between the temperature and water level reading in pressure transducer 1 , although $R^{2}=0.439$.

Cain et al. (2004) found a similar pattern as that shown for pressure transducer 3 when they tested a vented pressure transducer (Cain et al., 2004). They concluded that the fluctuation in the pressure head readings was caused by the

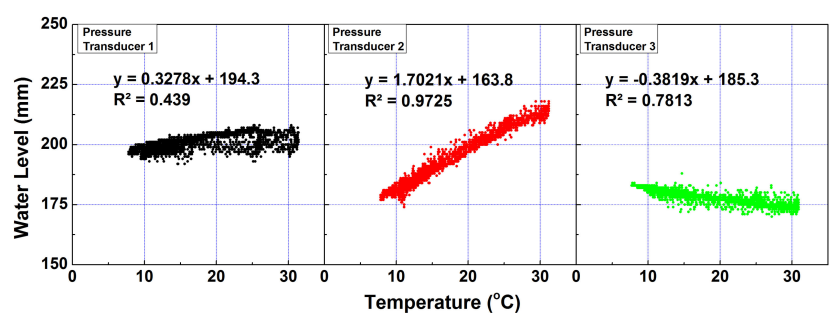

Figure 3. Relationships between temperature and water level readings.

expanding and contracting of air column inside the venting tube. When the temperature was high the sensor cable was heated and the air column expanded, which, thus, applied a positive pressure on the backside of the diaphragm. As a result of that, the output pressure head readings are smaller, which eventually presented an inverse relationship between temperature and pressure head. However, if this was the mechanism responsible for the relationships in Fig. 2, then all pressure transducers in the current study should exhibit a similar behavior, which they did not. In the study of Cain et al., cable color and length were all considered to contribute to the noise since darker colors can absorb more solar radiation and longer cables can create more resistance for air flow in the venting tube. Admittedly, the cable they used was much longer (123 and $23 \mathrm{~m}$ ) than the one used in this study $(10 \mathrm{~m})$. A simple mathematical analysis of the venting system provides some clues.

The pressure difference caused by the thermal expansion/extraction between the sensor diaphragm and the venting end can be derived by considering the movement of a small air column inside the cable. Figure 4 shows a schematic of the derivation.

For an air column with a length of $x$ to expand to a length of $x+\mathrm{d} x$, the force exerted along the cable wall can be given as

$F=\tau \cdot \mathrm{d} x \cdot 2 \pi R$,

where $F$ is the tangential force, $\mathrm{ML} \mathrm{T}^{-2} ; \tau$ is the shear stress, $\mathrm{MLT}^{-2} ; \mathrm{d} x$ is the expanded length, $L$; and $R$ is the radius of the cable, $L$.

Integrate the force exerted from $\mathrm{d} x$ to the whole cable length:

$$
\begin{aligned}
& \int_{0}^{\mathrm{L}} \tau \cdot \mathrm{d} x \cdot 2 \pi R=\Delta P \cdot A, \\
& A=\pi \cdot R^{2},
\end{aligned}
$$

where $L$ is the total length of the venting cable, $L ; A$ is the cross section of the venting cable, $\mathrm{L}^{2}$; and $\Delta P$ is the total pressure difference between the venting end and the sensor end, $\mathrm{MLT}^{-2}$. 


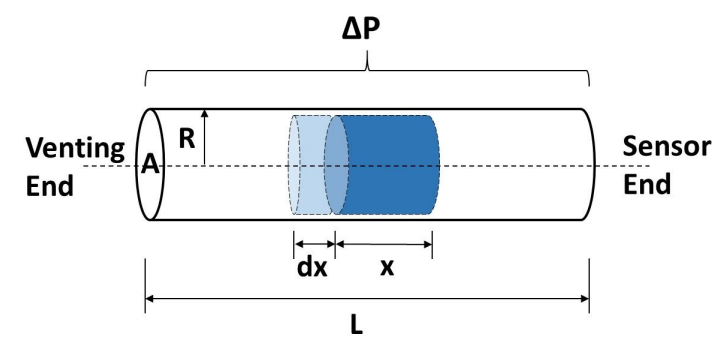

Figure 4. Schematic plot of the air movement inside the venting cable by thermal expansion.

Equation (2) can be re-written into the following format:

$\Delta P=\frac{2}{R} \int_{0}^{\mathrm{L}} \tau \cdot \mathrm{d} x$.

For an air column to expand from a length $x$ to a length $x+\mathrm{d} x$, the change of the volume can be expressed as

$\Delta V=\alpha \cdot \Delta T \cdot V$,

where $\Delta V$ is the volume change of the air, $\mathrm{L}^{3} ; \Delta T$ is the change of the temperature, $\mathrm{K}$; and $\alpha$ is a thermal expansion coefficient, $\mathrm{K}^{-1}$.

Given

$\Delta V=\mathrm{d} x \cdot A$,

and

$V=x \cdot A$,

Eq. (5) can be transformed into

$\mathrm{d} x \cdot A=\alpha \cdot \Delta T \cdot x \cdot A$.

Canceling $A$ and dividing both sides of the equation by $\mathrm{d} t$ we have

$v=\frac{\mathrm{d} x}{\mathrm{~d} t}=\alpha \cdot \frac{\mathrm{d} T}{\mathrm{~d} t} \cdot x$,

where $v$ is the average velocity of the moving air column, $\mathrm{L} \mathrm{T}^{-1}$.

The shear stress is related to the viscosity of air and the velocity profile by

$\tau=\mu \cdot \frac{\mathrm{d} v}{\mathrm{~d} r}$,

where $\mu$ is the viscosity of the air, $\mathrm{MLT}^{-1}$; and $\frac{\mathrm{d} v}{\mathrm{~d} r}$ is the velocity gradient along the cable radius, $\mathrm{T}^{-1}$.

Assuming the flow inside the cable is Poiseuille flow, the velocity profile can be expressed as

$V(r)=V_{0} \cdot\left(1-\left(\frac{r}{R}\right)^{2}\right)$,

where $V_{0}$ is the maximum velocity at the centerline of the flow, and $r$ is the radial position measured from the centerline.

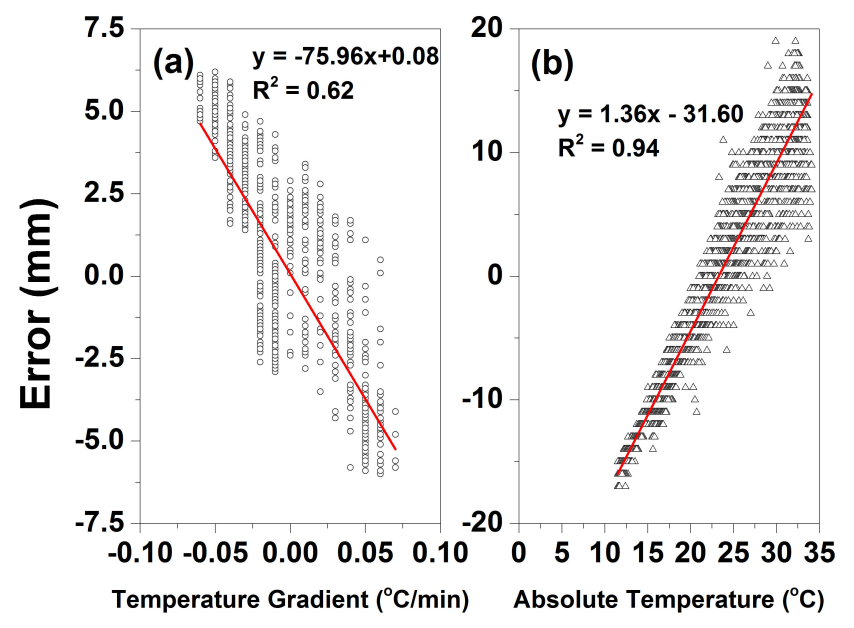

Figure 5. Errors in water level measurement associated with temperature gradient and absolute temperature. The temperature gradient was calculated over a $10 \mathrm{~min}$ interval.

Inserting Eq. (9) into Eq. (8) yields

$\tau=\mu \cdot \frac{-2 V_{0} r}{R^{2}}$.

In Poiseuille flow, the maximum velocity $V_{0}$ equals twice the mean velocity $v$. With this relationship, by combining Eqs. (7) and (10) we have

$\tau(r)=\frac{\mu \cdot-2 \cdot 2 \cdot \alpha \cdot \frac{\mathrm{d} T}{\mathrm{~d} t} \cdot x \cdot r}{R^{2}}$.

Considering the shear force exerted at the boundary of the air column and the cable wall where $r=R$, Eq. (11) can be written as

$\tau(R)=\frac{-4 \cdot \mu \cdot \alpha \cdot \frac{\mathrm{d} T}{\mathrm{~d} t} \cdot x}{R}$.

By inserting Eq. (12) into Eq. (4) we have

$\Delta P=\frac{2}{R} \int_{0}^{\mathrm{L}} \frac{-4 \cdot \mu \cdot \alpha \cdot \frac{\mathrm{d} T}{\mathrm{~d} t} \cdot x}{R} \cdot \mathrm{d} x$.

Solving the integration with respect to $x$ we can express $\Delta P$ in the following form:

$\Delta P=\frac{-4 \mu \alpha L^{2}}{R^{2}} \cdot \frac{\mathrm{d} T}{\mathrm{~d} t}$.

According to Eq. (14), we expect the errors associated with venting to be proportional to the thermal time derivative, the viscosity of air and inversely to the cross section area of the venting tube. Indeed, in Fig. 5a this is shown explicitly. Note that in this plot we use the temperature of water in lieu of an air temperature measurement. The errors associated with absolute temperature is shown in Fig. 5b. From the strong correlation we believe that differential thermal expansion of the 
strain gauge on the pressure transducer diaphragm can better explain the temperature effect seen in Fig. 2. The sensitivity of the strain gauge can be expressed as (Watson, 2008)

$F=\frac{\Delta R / R}{\varepsilon}$,

$\varepsilon=\Delta L / L$,

$R=\rho \cdot \frac{L}{A}$,

where $F$ is the strain sensitivity, also called the gauge factor; $R$ is the conductor resistance; $\varepsilon$ is the strain; $L$ is the conductor length; $\rho$ is the resistivity; and $A$ is the conductor area.

The changing of the ambient temperature causes resistance changes in the metal conductors from which the strain gauge is built. The variables in Eq. (17) are functions of temperature themselves. The transducer diaphragm where the strain gauge is bonded can also contract or elongate with temperature changes (Cappa et al., 1992; Richards, 1996; Vishay Micro-Measurement, 2007). This thermal output error is more prominent than that produced from the extraction or expansion of air column inside the venting tube in this experiment.

The derivation of Eq. (14) is under the assumptions that the air flow inside the tube can be considered as laminar Poiseuille flow and the velocity profile is fully developed inside the cable. Although these assumptions are sometimes difficult to meet in reality, the calculation provides a theoretical base for investigating the error source in pressure transducer measurements.

Figure 6 shows the long-term monitoring data of the water levels and the temperature in the bucket. After the bucket was exposed to sunlight on the roof for a few days, it was moved back indoors in the laboratory. The temperature in the laboratory is relatively stable compared to the outdoor conditions. Although the room temperature is not directly measured with a thermometer, the water temperature inside the bucket should be a good surrogate to reflect the changes. It is clearly shown in Fig. 6 that there are less fluctuations in temperature after the bucket was indoors and that the fluctuations resumed after the bucket was moved back to the outdoor conditions. Accordingly, the water level readings from the pressure transducers became more stable when they were in the controlled environment. The large peaks at the transition points were caused by moving the bucket. The small wiggles in the signal are expected as the resolution of the sensors is $1 \mathrm{~mm}$.

Pressure transducers 1 and 3 showed that they did not experience a significant baseline shift problem when the daily temperature change was not sharp, i.e., under indoor conditions. However, the baseline reading in pressure transducer 2 increased during the indoor monitoring period. The expanding and contracting of the air column inside the venting tube did not cause the baseline shift in pressure transducer 2 since the cables were not exposed to solar radiation and the room temperature change was not sharp during the monitoring.

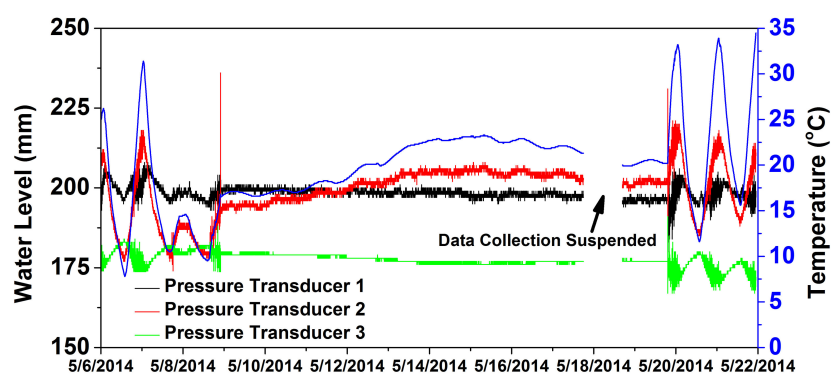

Figure 6. Time series of water level readings and water temperature in the bucket. The gap in the curves indicates the suspension of data collection.

After about 11 days, the bucket was moved outdoors where the daily temperature again had a pattern of sharp and rapid change as the solar radiation varied with the position of the sun. Almost immediately, the water level readings began to show more noise as the water temperature increased during the day. The noise pattern in all three pressure transducers is repeatable and similar to the previous observation. The fluctuations of the water level readings still showed either positive or negative relationships with the water temperature. The noise in the signal was larger when the temperature increased during the daytime and obviously smaller as the temperature decreased. Interestingly, although the water temperature data showed that the climbing and dropping parts of the curve were equally sharp, noise was most prominent when the temperature was increasing.

For submersible pressure transducers, the key component is a pressure sensitive diaphragm on the back of which are attached a series of strain gauges. The water head above the transducer causes a flexing across the diaphragm which is measured as an electrical signal and then converted to the water depth. Poor or nonexistent temperature compensation will generate thermal effects in pressure transducers. In the current study, the manufacturer likely used one compensation algorithm for the same model, and individual sensors vary in characteristics and calibration. So applying the same temperature compensation algorithm to these sensors would reduce some noises and errors, but the extent will vary in different sensors. For instance, pressure transducers 1 and 2 have the same design and they showed similar patterns of thermal effect on their output; however, the temperature compensation in pressure transducer 1 is better than in pressure transducer 2 as it showed smaller peaks in fluctuation and provided a stable baseline during the indoor test. Pressure transducer 3 seems to have a reversed compensation algorithm. Nonetheless, the changes in sensor output under the thermal effect in the laboratory test is mainly caused by the temperature change on the transducer element or circuit board components.

Geosci. Instrum. Method. Data Syst., 4, 65-73, 2015 


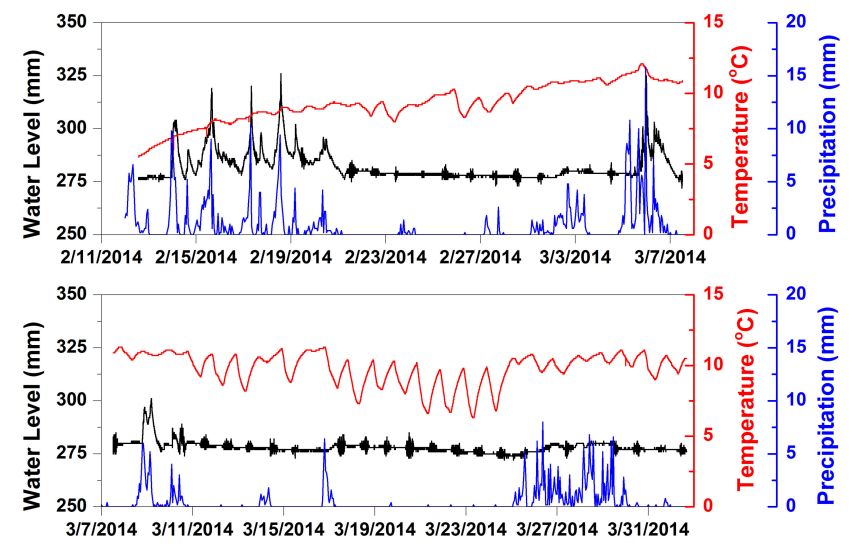

Figure 7. Long-term field monitoring data from the pressure transducer installed at the Alsea site on Oregon Highway 34. The black, red, and blue lines represent water level, temperature, and hourly precipitation, respectively. The continuous monitoring was divided into two plots to show more details.

\subsection{Field test results}

Under typical field conditions, natural events like precipitation (rainfall and snowfall), frosting, and evaporation will affect the pressure transducer output. Additionally, the pressure transducer is exposed to more severe and extreme weather, especially during wintertime in cold regions. Because the function of the pressure transducer in this field test is to monitor stormwater runoff, the inflow water from the collection pipes is another factor that will change the water level readings.

Our long-term field monitoring data are shown in Fig. 7. The pressure transducer used in the field test is pressure transducer 3, as in the above laboratory test. The specification of this model states that the pressure transducer cannot be operated below freezing point because ice crystals would form and permanently damage the transducer (Freeman et al., 2004). To avoid this situation which is likely to occur, since the site in located in a remote mountain area, the sensor was submerged into the water in the flow container and the bottom part of the container, where the sensor is, was buried into the ground to a depth of $40 \mathrm{~cm}$. The soil functions like an insulation layer, protecting the water inside the container from freezing. The temperature readings in Fig. 7 show that, even during the cold days in winter, the water did not freeze in the container; thus, the sensor was safe.

The large peaks in the water level readings are produced by the inflowing runoff water. Most of the runoff peaks corresponded with precipitation peaks recorded by a rain gauge on site. Note that not all the precipitation peaks will translate into runoff peaks since runoff was affected by the antecedent soil moisture content. When intense rainfall occurred during the wet winter days (12-21 February 2014), the water content in the soil of the highway shoulder was also high and sometimes reached saturation. The low ambient temperature

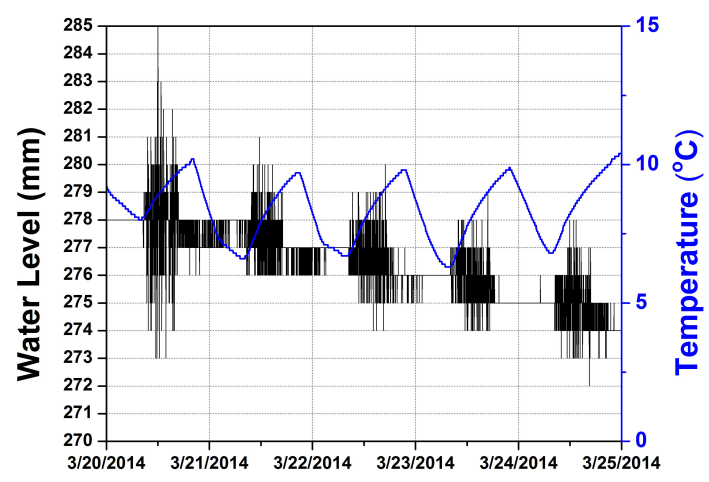

Figure 8. Water level and temperature readings during a 5-day period at the Alsea site on Oregon Highway 34.

during these days hardened the surface soil, which also contributed to the low infiltration rate. Under such situations, consecutive rainfall events will generate more surface runoff, as shown in the upper plots in Fig. 7. During the days when there is no or limited precipitation, as shown in the period from 22 to 28 February 2014, the soil moisture content decreased as evaporation and drainage depleted the water from the soil, which re-activated the ability of the highway shoulder strip to store storm runoff water. So when it rained for few days from 1 to 3 March 2014, no significant runoff was observed. And when the dry period was short, from 3 to 4 March 2014, the following rainfall produced more runoff peaks as shown in the figure. Similar observations can also be seen in the lower plot in Fig. 7.

The baseline water level during this long-term field monitoring is fairly stable. A drop in the scale of millimeters in the baseline reading was expected as the evaporation under the field condition is inevitable. The intermittent precipitation replenished the water level in the flow container. Interestingly, during the days when there was no precipitation, we still observed a noise pattern in the transducer output which showed a periodic correlation with the temperature signal. The magnitude of the noise is more prominent when the temperature change is sharper. When temperature is relative constant or has less fluctuations, the noise is smaller.

Figure 8 presents an enlarged time series from 20 to 24 March 2014 when no precipitation occurred. The baseline gradually decreases at $1 \mathrm{~mm} \mathrm{day}^{-1}$ steps due to the evaporation from the flow container. The diurnal temperature pattern correlated with the noise in the water level readings. For a temperature range from 6.3 to $10.1{ }^{\circ} \mathrm{C}$, the noise can be as large as $7 \mathrm{~mm}$ (accuracy of this sensor is $\pm 7 \mathrm{~mm}$ ) and as small as $1 \mathrm{~mm}$. When temperature varied rapidly in a wider range as shown in Fig. 6, the noise is much larger and sometimes exceeded the accuracy level of this sensor. A similar pattern can also be seen in the pressure transducer installed at the Santiam site on Oregon Highway 22 (Fig. 9). Without considering the temperature effect, the peaks in the water level reading could be mistaken as inflow runoff water. 


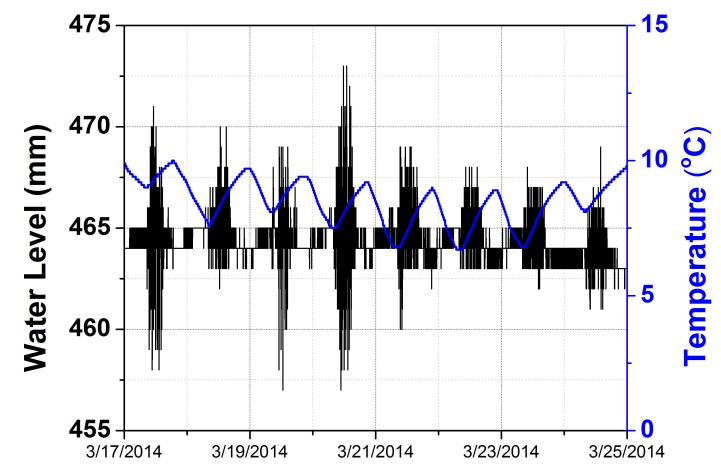

Figure 9. Water level and temperature readings during a 7-day period at the Santiam site on Oregon Highway 22.

In groundwater or deep well monitoring, the water temperature is relatively stable and oftentimes the researcher looks at water level fluctuation on a much larger scale, from a few centimeters to a few meters (Schaefer and Hemond, 1986; Novakowski and Gillham, 1988; Rasmussen and Crawford, 1997). In those cases, submersible pressure transducers are well suited for data collection. However, in surface water monitoring where fine-scale data are needed (Gribovszki et al., 2013), the variable water temperature could be a problem because inadequate temperature compensation will affect the performance of the submersible pressure transducer. As the water level data often will be converted into flow rate in streams or runoff, the small errors or noise will be amplified through the calibration curve, which eventually will lead to misinterpretation of the results.

During the monitoring at the Santiam site, two snowstorm events were recorded. The pressure transducer is very vulnerable under a severe weather condition, especially when the ambient temperature decreases rapidly and sometimes below the freezing point.

Figure 10 shows the effect of the snowfall event on the performance of the pressure transducer during one of the two recorded snowfall events. The ambient temperature fell below the freezing point. According to the water temperature data, the bottom part of the flow container and the water inside it were not frozen during the snowfall even when the air temperature was below $0{ }^{\circ} \mathrm{C}$. This is corroborated by the soil temperature sensor installed nearby. However, it is believed that an ice lens formed at the water surface. The pressure transducer could still register the pressure fluctuations because it was submerged in the relatively deep water. But the reliability of the data was lowered since the ice lens can introduce errors.

The large peaks highlighted with the dashed line box illustrate how the transducer performed during and after snow events. The readings reached up to $4000 \mathrm{~mm}$ in those large peaks, whereas the upper measurement limit is $3500 \mathrm{~mm}$ in this pressure transducer.

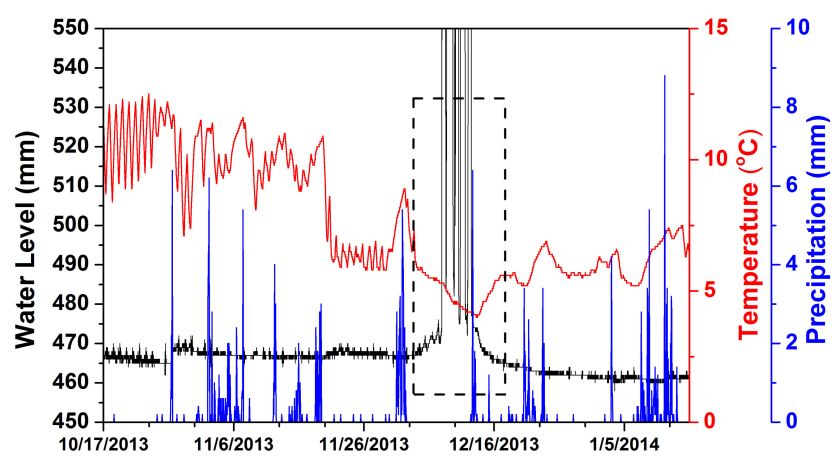

Figure 10. Effect of snowfall event and low temperature on the performance of the pressure transducer at the Santiam site on Oregon Highway 22. The black line is the water level inside the flow container, the red line is the water temperature, and the blue line is the precipitation. The large peaks were topped off to show other details in the black curve. The dashed line box shows the period where the sensor is affected by the snow event.

Here, the error was created by the development of the ice layer within the container, frosting and/or the frozen thin water film around the venting port. The venting tube is normally very small in diameter and is in direct contact with the transducer component. This may not be a problem in a dry and warm environment; however, under cold and wet climate, the moisture is likely to accumulate and block the thin venting tube, which would be another error source (Katsuta and Tshihara, 1986). The pressure transducer at the Santiam site was not damaged by the snowfall event and cold temperature because it was protected by the in-ground installation.

Without a cold-protection and desiccation system, using a vented submersible pressure transducer for surface water monitoring such as in the current study carries the risk of losing data or pressure transducer damage.

\section{Conclusions}

The results of the laboratory and field tests indicate that temperature has a clear effect on the performance of vented submersible pressure transducers. The noise or errors in the sensor output caused by thermal effects bring uncertainties into the experiment's results, especially in fine-scale surface water monitoring where the water head change can be very small (in millimeter scale). Small errors in water level measurements may lead to large uncertainties in the calculated flow velocity either in a stream or v-notch weir equipment, sometimes the uncertainty can be up to $100 \%$ (Sweet et al., 1990; Grant and Dawson, 2001).

The rapid increase of temperature produces more noise in the transducer output, and the magnitude of the fluctuations in the water level readings can sometimes exceed the accuracy specification of the sensor. When the pressure transducers are operated in an environment where temperature is rel- 
atively stable, the output contains much less noise. Therefore, the fluctuation of the signal is within the measurement resolution. Individual sensors have different responses to the temperature fluctuation due to differing individual compensation errors. Both positive and negative relationships were observed between the temperature and sensor output. Under extreme climate conditions where ambient temperature can drop below freezing point, the pressure transducer can generate erroneous outputs due to the impaired contact with the atmosphere through the venting cable.

From the discussion presented above, it is notable that the measurement of the water level or hydraulic head, especially at a fine scale, is not simple. Errors can still be generated from environmental factors even if all other operation procedures are carefully followed. Influencing factors such as temperature are not negligible under field conditions. Several recommendations for using a vented pressure transducer in the field are provided here based on the preceding experience.

1. If not integrated inside the sensor with the pressure transducer, a temperature probe is recommended to be installed in the water where the pressure transducer is located. Because the noise and error brought by temperature effects normally have a pattern and are predictable, they can be corrected if the water temperature is recorded simultaneously.

2. It is important to keep moisture from entering the venting tube for the pressure transducer, especially for installations in wet and cold climates. A desiccation system for the venting ports on the sensor cable can provide reliable data output for long-term monitoring (frequently checking and replacing the desiccants after intensive precipitation).

3. Ensure the pressure transducer is protected from temperatures below the freezing point. When installing pressure transducers to measure water levels in surface flow devices such as weirs and flumes, try to position the pressure transducer deep into the ground. The soil layers are good insulation. Together with the desiccation system, the results should be reliable for scientific analyses and reports. The ice lens formation on the water surface is sometimes inevitable, extra examination is needed for data collected during cold days.

4. Even for the same model, individual pressure transducers can have their own response characteristics to the temperature fluctuation. Customized calibration for noise level and baseline drift in the laboratory and field are recommended before the final installation for each sensor.

5. Test the pressure transducers for at least a few days to examine the output fluctuation over the temperature range expected in the field installation. In this way, the behavior and performance can be estimated for a wide range and data can be calibrated and corrected correspondingly.

Acknowledgements. We thank Decagon Devices Inc. for providing the CTD sensors for testing. This research is supported by the Oregon Department of Transportation.

Edited by: L. Eppelbaum

\section{References}

Cain III, S. F., Davis, G. A., Loheide II, S. P., and Bulter Jr., J. J.: Noise in pressure transducer readings produced by variations in solar radiation, Ground. Water., 42, 939-944, 2004.

Cappa, P., De Rita, G., McConnell, K. G., and Zachary, L. W.: Using strain gages to measure both strain and temperature, Exp. Mech., 32, 230-233, 1992.

Freeman, L. A., Carpenter, M. C., Rosenberry, D. O., Rousseau, J. P., Unger, R., and McLean, J. S.: Use of submersible pressure transducers in water-resources investigations, USGS, Techniques of Water-Resources Investigations 8-A3, USGS, Reston, Virginia, 65 pp. 2004.

Grant, D. M. and Dawson, B. D.: Isco Open Channel Flow Measurement Handbook, 5th Edn., Isco, Lincoln, Nebr., 501 pp., 2001.

Gribovszki, Z., Kalicz, P., and Szilágyi, J.: Does the accuracy of fine-scale water level measurements by vented pressure transducers permit for diurnal evapotranspiration estimation?, J. Hydrol., 488, 166-169, 2013.

Katsuta, K. and Tshihara, I.: Studies on pressure drops in air flowing through inside tubes with frosting, Paper 19, in: International Refrigeration and Air Conditioning Conference, Purdue University, West Lafayette, Indiana, 8 pp., 1986.

McDonald, J. P.: Comparison of vented and absolute pressure transducers for water-level monitoring in Hanford Site Central Plateau Wells, Technical Report SGW-49700, CH2M HILL Inc., Richland, Washington, 40 pp., doi:10.2172/1028215, 2011.

McLaughlin, D. L. and Cohen, M. J.: Thermal artifacts in measurements of fine-scale water level variation, Water Resour. Res., 47, W09601, doi:10.1029/2010WR010288, 2011.

Novakowski, K. S. and Gillham, R. W.: Field investigations of the nature of water-table response to precipitation in shallow watertable environments, J. Hydrol., 97, 23-32, 1988.

Post, V. E. A. and von Asmuth, J. R.: Review: hydraulic head measurements - new technologies, classic pitfalls, Hydrogeol. J., 21, 737-750, 2013.

Rasmussen, T. C. and Crawford, L. A.: Identifying and removing barometric pressure effects in confined and unconfined aquifers, Groundwater, 35, 502-511, 1997.

Richards, W. L.: A new correction technique for strain-gage measurements acquired in transient-temperature environments, Technical Paper 3593, NASA, Washington, D.C., 1996.

Rosenberry, D. O.: Effect of sensor error on interpretation of longterm water-level data, Ground Water, 28, 927-936, 1990.

Schaefer, M. E. and Hemond, H. F.: A low-cost system to remotely measure piezometric head, Groundw. Monit. Remediat., 6, 8791, 1986. 
Sorensen, J. P. R. and Butcher, A. S.: Water level monitoring pressure transducers: a need for industry-wide standards, Groundw. Monit. Remediat., 31, 56-62, 2011.

Stewart, R. D., Liu, Z., Rupp, D. E., Higgins, C. W., and Selker, J. S.: A new instrument to measure plot-scale runoff, Geosci. Instrum. Method. Data Syst. Discuss., 4, 589-608, doi:10.5194/gid-4-589-2014, 2014.

Sweet, H. R., Rosenthal, G., and Atwood, D. F.: Water level monitoring: achievable accuracy and precision, in: Groundwater and Vadose Zone Monitoring, ASTM STP 1053, edited by: Nielsen, D. M. and Johnson, A. I., American Society for Testing and Materials, Philadelphia, 190-191, 1990.
Vishay Precision Group, Inc.: Strain gage thermal output and gage factor variation with temperature, Tech. Note TN-504-1, Vishay Precision Group, USA, 2007.

Watson, R. B.: Bonded electrical resistance strain gages, in: Chapter 12, Handbook of Experimental Solid Mechanics, Springer, New York, 292-294, 2008. 